\title{
Physical and Mental Health Effects of Bushfire and Smoke in the Australian Capital Territory 2019-20
}

\author{
Rachael M. Rodney ${ }^{1,2 *}$, Ashwin Swaminathan ${ }^{3}$, Alison L. Calear ${ }^{4}$, Bruce K. Christensen ${ }^{5}$, \\ Aparna Lal ${ }^{1}$, Jo Lane ${ }^{1}$, Zoe Leviston ${ }^{5}$, Julia Reynolds ${ }^{5}$, Susan Trevenar ${ }^{1}$, \\ Sotiris Vardoulakis ${ }^{1}$ and lain Walker ${ }^{5}$ \\ ${ }^{1}$ National Centre for Epidemiology and Population Health, Research School of Population Health, The Australian National \\ University, Canberra, ACT, Australia, ${ }^{2}$ Fenner School of Environment and Society, The Australian National University, \\ Canberra, ACT, Australia, ${ }^{3}$ Departments of General Medicine and Infectious Diseases, The Canberra Hospital, Canberra, \\ ACT, Australia, ${ }^{4}$ Centre for Mental Health Research, Research School of Population Health, The Australian National University, \\ Canberra, ACT, Australia, ${ }^{5}$ Research School of Psychology, The Australian National University, Canberra, ACT, Australia
}

The 2019-20 bushfire season in south-eastern Australia was one of the most severe in recorded history. Bushfire smoke-related air pollution reached hazardous levels in major metropolitan areas, including the Australian Capital Territory (ACT), for prolonged periods of time. Bushfire smoke directly challenges human health through effects on respiratory and cardiac function, but can also indirectly affect health, wellbeing and quality of life. Few studies have examined the specific health effects of bushfire smoke, separate from direct effects of fire, and looked beyond physical health symptoms to consider effects on mental health and lifestyle in Australian communities. This paper describes an assessment of the health impacts of this prolonged exposure to hazardous levels of bushfire smoke in the ACT and surrounding area during the 2019-20 bushfire season. An online survey captured information on demographics, health (physical and mental health, sleep) and medical advice seeking from 2,084 adult participants (40\% male, median age 45 years). Almost all participants (97\%) experienced at least one physical health symptom that they attributed to smoke, most commonly eye or throat irritation, and cough. Over half of responders self-reported symptoms of anxiety and/or feeling depressed and approximately half reported poorer sleep. Women reported all symptoms more frequently than men. Participants with existing medical conditions or poorer self-rated health, parents and those directly affected by fire (in either the current or previous fire seasons) also experienced poorer physical, mental health and/or sleep symptoms. Approximately $17 \%$ of people sought advice from a medical health practitioner, most commonly a general practitioner, to manage their symptoms. This study demonstrated that prolonged exposure to bushfire smoke can have substantial effects on health. Holistic approaches to understanding, preventing and mitigating the effects of smoke, not just on physical health but on mental health, and the intersection of these, is important. Improved public health messaging is needed to address uncertainty about how individuals can protect their and their families health for future events. This should be informed by identifying subgroups of the population, such as those with existing health conditions, parents, or those directly exposed to fire who may be at a greater risk.

Keywords: bushfire, wildfire, natural disaster, biomass smoke, respiratory health, mental health, Australia 


\section{INTRODUCTION}

During the summer of late 2019 and early 2020, extensive areas of south-eastern Australia experienced one of the most severe bushfire seasons in recorded history. Over 10 million hectares of land were burnt, and over 2,400 homes were destroyed in New South Wales (NSW) alone. Bushfire smoke-related air pollution reached hazardous levels in major metropolitan areas including Canberra, Australia's capital, in the Australian Capital Territory (ACT). Between 15 December and 15 February in the ACT, $27 \%$ of days ( $n=17 / 63$ days) had air quality levels that were considered extremely poor $\left(\geq 300 \mathrm{PM}_{2.5} \mu \mathrm{g} / \mathrm{m}^{3}\right)$ and on three quarters of days ( $n=47 / 63$ days), air quality was classified as poor or worse $\left(\geq 50 \mathrm{PM}_{2.5} \mu \mathrm{g} / \mathrm{m}^{3}\right)$ at one or more of Canberra's three air quality monitoring stations (1) [using thresholds defined by NSW Department of Planning, Industry and Environment (2)]. On the worst days, hourly levels reached well over $1000 \mathrm{PM}_{2.5}$ $\mu \mathrm{g} / \mathrm{m}^{3}$.

Bushfire is an inevitable and essential part of natural Australian ecosystems; however, the severity and duration of fire seasons are projected to increase globally with climate change (3). A recent study concluded that as a result of anthropogenic climate change, the prevalence of days of high-risk bushfire weather has increased, conservatively, by at least 30\% since 1900 (4). As a result of predicted changes to bushfire patterns, the health and community impacts of bushfire are likely to increase unless effective adaptation measures are implemented. The public health impacts of bushfire extend beyond direct exposure to the fire itself, with increasing awareness of the effects of bushfire smoke-related air pollution (5). Smoke can travel long distances and affect large populations, even in urban areas geographically separated from fire (6). Bushfire smoke can have considerable impacts on health; it is estimated 340,000 deaths can be attributed to bushfire smoke globally each year (7). Fine particulate matter, i.e., particles $<2.5$ micrometers in diameter $\left(\mathrm{PM}_{2.5}\right)$, can adversely affect health via impaired respiratory and cardiac functioning, promotion of inflammation, and alteration of immune function $(8,9)$. Bushfire-related air pollution has also been associated with increases in mortality (10-12) and the effects of smoke can be more severe in populations with particular vulnerability, such as those with preexisting medical conditions including cardiovascular disease or respiratory conditions $(13,14)$.

In bushfire events, it can be difficult to separate the health effects associated with direct displacement, loss, or exposure to fire from those of bushfire smoke. Most studies examining the effects of bushfire smoke on health have used routinely collected health data such as emergency department presentations, hospital admissions and mortality (5), which are very likely to underestimate the effects on the population by capturing only those affected severely enough to require seeking secondary or tertiary-level health care. Prior studies have also focused primarily on physical health concerns, with few studies taking a holistic approach to the assessment of health by including measures of mental health and lifestyle in addition to physical health.
The 2019-20 bushfire season affecting south-eastern Australia elicited widespread public concern due to its duration, and uncertainty about potential immediate and long-lasting health effects of prolonged smoke exposure. In addition, individuals experienced considerable uncertainty about how to protect the health and wellbeing of themselves and their families during this period (15). A preliminary evaluation of the air pollution health burden in eastern Australia estimated that bushfire smoke was responsible for 417 (95\% CI, 153-680) excess deaths, over 3,000 excess hospitalizations for cardiovascular $(1,124 ; 95 \% \mathrm{CI}$, 211-2,047) and respiratory (2,027; 95\% CI, 0-4,252) problems, and 1,305 (95\% CI, 705-1,908) presentations to emergency departments with asthma (16). The total smoke-related physical health costs during the 2019-20 bushfire period have been estimated at AU $\$ 1.95$ billion (17). The 2019-20 bushfires were of particular interest in the Canberra and surrounding community, as this area experienced a severe bushfire in January 2003. During this earlier disaster, almost 160,000 hectares of land were burnt, 448 houses were destroyed (and a much greater number damaged), over 5,000 people were evacuated, four people died and hundreds of people received medical care (18).

This paper presents the findings of a cross-sectional study examining the effects of prolonged exposure to hazardous levels of bushfire smoke-related air pollution on the physical health, mental health, and sleep patterns of residents of the ACT region during the 2019-20 bushfire season and how these vary by demographic and lifestyle factors.

\section{MATERIALS AND METHODS}

\section{Study Design}

This cross-sectional survey asked participants about their experiences during a "period of interest" defined as 15 December 2019 to 15 February 2020, as this was the period during which the most significant levels of bushfire smoke-related air pollution (hereafter referred to as "smoke") affected the Canberra region.

\section{Participant Recruitment}

The survey was conducted over a six-week period in March and April 2020. The sampling frame included all adult residents of the ACT and immediately adjacent regions of NSW. Inclusion criteria were: aged 18 years or older, able to understand an online questionnaire in English, and a residential address defined by specific postcode areas constituting the ACT and immediately surrounding postcodes (2600-2612, 2614-2620, 2626, 29002906, 2911-2914).

Participants were recruited using three methods: (i) LetterAn invitation to complete the online survey was posted to a random selection of 10000 addresses, selected from the ACTmapi database ("ACT Addressing" from ACTmapi (C)Australian Capital Territory). Any addresses identified as non-residential (e.g., businesses, schools) were removed and replaced prior to the mail out; (ii) Panel-A representative population sample of participants recruited by an external company; (iii) General-A convenience sample of the population was recruited via social media, radio advertisements and word of mouth, including interest from local media. 


\section{Data Collection}

Potential participants were invited to complete the online survey via REDCap electronic data capture tools hosted at Australian National University (19). The survey was available in English and in an online format only. Participants provided consent by submitting a completed survey. Two participants that received a letter mailout invitation and who did not have internet access completed the survey by phone with a study team member recording their responses.

The survey collected: postcode of residence, age (years), highest level of education achieved (no school qualification/ school or intermediate/ HSC or leaving certificate/ trade or apprenticeship/ certificate or diploma/ university or higher), tobacco smoking (never/past/current), rental status (renter/owner-occupier/other), pregnancy status (self/partner/none/not applicable), parental (yes/no and age of youngest child) or carer status (yes/no); previous medical diagnoses [asthma/chronic obstructive pulmonary disease (COPD-including emphysema and chronic bronchitis)]/allergies or hay fever/other respiratory disease (e.g., pleurisy, bronchiectasis, pulmonary fibrosis)/multiple sclerosis/arthritis/diabetes/other), engagement with a professional for a mental health concern during the last 12 months (yes/no) and self-rated health (poor/fair/good/very good/excellent); prior exposure to bushfire (no previous exposure to bushfire/been in an area with fire nearby/evacuated due to bushfire/experienced loss of or damage to property/had direct contact with bushfire (e.g.,firefighter or protecting property)/other) including whether this was during the 2003 Canberra bushfire (yes/no); direct exposure to bushfire in the current season (not affected/voluntarily relocated/forced to evacuate/damage to or loss of property/family or close friend affected/had to cancel or alter travel or holiday plans/ firefighter or first responder/other); effects of smoke on physical health (eye irritation or watery eyes/throat irritation or dry throat/cough/wheeze or whistling chest/sneezing/chest tightness or pain/breathlessness/headache/diarrhea or gastroenterological symptoms/other condition not listed), sleep (disrupted or poor sleep/fatigue or feeling tired) and mental health (anxiety/feeling depressed) symptoms and whether these were attributed to smoke (yes/no/unsure); health advice sought as a result of symptoms (yes/no, hospital inpatient/emergency department/general practitioner/specialist $/ 24 \mathrm{~h}$ health advice hotline/pharmacist/mental health professional e.g., psychologist/other health professional).

\section{Data Analysis \\ Data Management}

Summary statistics were used to describe the study's participants (Table 1) using demographic, health and lifestyle variables as described in Table 2. To explore physical health outcomes, data were divided into quartiles based on the cumulative number of physical health symptoms reported. A mental health outcome variable was created by including those who self-reported anxiety and/or feeling depressed as a result of smoke. Similarly, a sleep outcome variable was created by combining those who reported
TABLE 1 | Description of sample characteristics.

\begin{tabular}{|c|c|}
\hline Factor & $n(\%)$ \\
\hline \multicolumn{2}{|l|}{ Gender } \\
\hline Male & $831(40.2)$ \\
\hline Female & $1,231(59.6)$ \\
\hline Other & $4(0.2)$ \\
\hline Age (years) & $\begin{array}{l}45 \text { (SD 16.8) } \\
\min 18, \max \\
85\end{array}$ \\
\hline $18-24$ & $128(6.1)$ \\
\hline $25-34$ & $396(19.0)$ \\
\hline $35-44$ & $328(15.7)$ \\
\hline $45-54$ & $310(14.9)$ \\
\hline $55-64$ & $427(20.5)$ \\
\hline $65-74$ & $381(18.3)$ \\
\hline $75+$ & $113(5.4)$ \\
\hline \multicolumn{2}{|l|}{ Education } \\
\hline $\begin{array}{l}\text { No school qualification, school or intermediate, } \\
\text { HSC or leaving }\end{array}$ & $266(12.9)$ \\
\hline Trade, apprenticeship, certificate or diploma & $346(16.8)$ \\
\hline University & $1,451(70.3)$ \\
\hline Parent (Yes) & $548(26.5)$ \\
\hline \multicolumn{2}{|l|}{ Age of youngest child } \\
\hline 0-18 month & $113(20.8)$ \\
\hline$>18$ month -4 years & $123(22.7)$ \\
\hline $5-11$ years & $176(32.4)$ \\
\hline $12-17$ years & $131(24.1)$ \\
\hline Carer (Yes) & $317(15.4)$ \\
\hline Pregnant (Self) & $43(2.1)$ \\
\hline \multicolumn{2}{|l|}{ Self-rated health } \\
\hline Poor-Fair & $205(10.6)$ \\
\hline Good-Excellent & $1,730(89.4)$ \\
\hline $\begin{array}{l}\text { Previous diagnosis of a physical health } \\
\text { condition (Yes) }\end{array}$ & $1,241(62.5)$ \\
\hline $\begin{array}{l}\text { Previous diagnosis of a mental health } \\
\text { condition (Yes) }\end{array}$ & $441(29.4)$ \\
\hline Renter (Yes) & $295(22.2)$ \\
\hline \multicolumn{2}{|l|}{ Smoker } \\
\hline Never & $1,490(72.3)$ \\
\hline Past & $512(24.9)$ \\
\hline Current & $58(2.8)$ \\
\hline \multicolumn{2}{|l|}{ Direct fire exposure-current season } \\
\hline None & $859(41.7)$ \\
\hline Mild & $1,032(50.1)$ \\
\hline Severe & $168(8.2)$ \\
\hline \multicolumn{2}{|l|}{$\begin{array}{l}\text { Cumulative direct fire exposure in current } \\
\text { season (number of experiences) }\end{array}$} \\
\hline 0 & $880(42.2)$ \\
\hline 1 & $787(37.8)$ \\
\hline 2 & $315(15.1)$ \\
\hline 3 & $88(4.2)$ \\
\hline 4 & $13(0.6)$ \\
\hline 5 & $1(0.1)$ \\
\hline
\end{tabular}

(Continued) 
TABLE 1 | Continued

\begin{tabular}{ll}
\hline Factor & $\boldsymbol{n}$ (\%) \\
\hline Previous Fire Exposure & \\
None & $686(33.0)$ \\
Mild & $1,173(56.5)$ \\
Severe & $217(10.5)$ \\
Exposure to 2003 Canberra bushfires (Yes) & $905(43.4)$ \\
Cumulative previous fire exposure (number of & \\
experiences) & \\
0 & $689(33.1)$ \\
1 & $1,271(61.0)$ \\
2 & $98(4.7)$ \\
3 & $24(1.2)$ \\
4 & $2(0.1)$ \\
\hline
\end{tabular}

disrupted or poor sleep and/or fatigue or feeling tired. Although scaled, validated measures, especially of mental and physical health status, are generally preferable, this paper reports results of a rapid research response developed during the bushfire crisis, with the intention of reporting responses during or soon after the emergency in a way that would be helpful for future researchers and public health officials. Accordingly, our outcomes measures are brief assessments. They were developed from the research team's expertise in different contexts, and are based on our previous research $(13,15,20)$.

\section{Statistical Analysis}

All analyses were conducted in Stata (v15.1, College Station, TX StataCorp LLC). Summary statistics were used to describe the study sample as detailed in Table 1. Number (\%) were used to describe categorical variables and mean (SD) to describe continuous data. Descriptive statistics were calculated to examine the prevalence of self-reported physical health, sleep and mental health symptoms, overall and for men and women which were compared using $\mathrm{Chi}^{2}$ analyses. Ordinal logistic regression was used to identify factors (as per Table 2) that were associated with higher physical health symptoms. Bivariate analyses including age, gender and age*gender interaction were then conducted for factors for which $\mathrm{p} \leq 0.1$. Logistic regression was used to determine factors that were associated with either disrupted sleep or mental health symptoms. Similar bivariate analyses were conducted to develop sleep and mental health models. Summary statistics [n (\%)] were used to describe sources of health advice sought, overall and separately for males and females, which were compared using $\mathrm{Chi}^{2}$ analyses.

\section{RESULTS}

\section{Population}

A total of 2,095 completed responses to the survey were received; $644(30.7 \%), 639(30.5 \%)$, and $812(38.8 \%)$ people recruited via the panel, letter and general recruitment methods respectively. This was a response rate of approximately $6.4 \%$ to the letter invitations, although many were returned to sender so it was unclear how many were undelivered. Eleven responses were excluded as the participant resided outside of the target area or did not provide a valid postcode. This resulted in a total sample of 2,084 responses that were included in subsequent analyses.

Participant characteristics are summarized in Table 1. Of the study participants, $40.2 \%$ were male, $59.6 \%$ were female, and $0.2 \%$ identified as being of another gender. The mean age of respondents was 45 years (median 45, range 18-85 years), approximately 10 years older than the median age of ACT residents. Approximately $13 \%$ of the sample had completed a high school certificate or less, $17 \%$ a trade, apprenticeship, certificate or diploma, and $70 \%$ had completed a University degree. This suggests that the sample included a greater proportion of women, was on average older, and more highly educated than the ACT population compared with data from the Australian Bureau of Statistics (21).

Approximately a quarter of respondents were parents, $15.4 \%$ were carers for one or more non-child dependents and $22 \%$ of participants rented their place of residence. Forty-three respondents $(2.1 \%)$ were pregnant during the period of interest, $11 \%$ rated their own health as poor-fair (vs $89 \%$ good-excellent), $3 \%$ were current smokers, $25 \%$ were ex-smokers and $72 \%$ had never smoked. Over half of the sample (58\%) had been directly affected by fire (not just smoke) during the 2019-20 bushfire season, with $8 \%$ of the total sample reporting being affected severely. Previous direct exposure to bushfire had been reported by $67 \%$ of the sample, $10.5 \%$ severely. For most participants $(43 \%$ of the total sample), this exposure had been during the 2003 Canberra bushfire event.

\section{Physical Health}

Most participants (97.1\%) reported experiencing at least one specified physical health symptom during the period of interest that they attributed to the smoke (Table 3). The most common symptoms were eye irritation or watery eyes $(73.1 \%)$, throat irritation or dry throat (70.4\%) and cough (50.6\%). A considerable proportion of people also reported experiencing headaches (38.2\%), breathlessness $(21.9 \%)$, sneezing $(21 \%)$ or wheeze/whistling chest (19.9\%). A small number of people (3.2\%) also reported experiencing other (non-itemized) physical or mental health impacts of the smoke including asthma, bronchitis, itchy skin/rash, runny nose, sinusitis and mental trauma. Women reported all physical symptoms more frequently than men $(p<0.001$ for all other than sneeze $p<0.05)$ and had almost three times the odds of men of experiencing a greater number of physical health conditions as a result of exposure to smoke $(2.92 \pm 0.344, p<0.001)$ (Table 4). After accounting for age and gender, those participants with poorer self-rated health $(2.13 \pm 0.344, p<0.001)$, a previous diagnosis of either a physical $(2.18 \pm 0.266, p<0.001)$ or mental health condition $(1.64 \pm 0.206, p<0.001)$, or were a past (but not current) smoker (1.83 \pm 0.226 ; $p<0.001)$, had greater odds of experiencing more physical symptoms. Any direct exposure with fire this season increased odds of experiencing a greater number of health symptoms (1.64 \pm $0.186, p<0.001)$. The effect was strongest in those who had experienced more severe effects of bushfire compared to those 
TABLE 2 | Details of variables used to describe the study population in regression models.

\begin{tabular}{|c|c|}
\hline Variable & Description \\
\hline Gender & Due to the small number of "other" responses, gender was included in regression models as binary variable (male vs. female) \\
\hline Age & Explored as either continuous (years) or categorical (18-24, then 10 year bins (e.g., 25-34) up to 75+ years) variables \\
\hline Parent & No vs. yes (parent of one or more children under 18 years) \\
\hline Parent age & Age of youngest child grouped into 0-18 months, under 5 years, $5-11$ years, $12-17$ years \\
\hline Carer & No vs. yes (carer of one or more non-child dependents) \\
\hline Pregnant & No vs. yes (self-pregnant) \\
\hline Self-rated health & Grouped into two groups; fair and poor vs. excellent, very good and good \\
\hline $\begin{array}{l}\text { Previous physical } \\
\text { health diagnosis }\end{array}$ & No vs. yes (one or more previous diagnoses) \\
\hline $\begin{array}{l}\text { Previous mental health } \\
\text { diagnosis }\end{array}$ & No vs. yes (engagement with a professional for a mental health concern during the last 12 months) \\
\hline Renter & Two categories-owner-occupier vs. renter \\
\hline Smokers & Three categories-never, past, current \\
\hline Education & $\begin{array}{l}\text { The level of education completed was grouped into: no school qualification, school or intermediate, HSC or leaving; vs. Trade or } \\
\text { apprenticeship, certificate or diploma; vs. university or higher }\end{array}$ \\
\hline Direct fire exposure & $\begin{array}{l}\text { Direct exposure to fire in the current season was measured as: } 1 \text {. Any exposure-yes/no if any direct exposures to fire were indicated; } 2 \text {. } \\
\text { Scale-a scale was created consisting of three levels of exposure-none (none or indirect), mild (classified as responses limited to being in } \\
\text { an area with fire nearby, evacuation due to bushfire, area of significance lost other than home, family member was affected, home was } \\
\text { affected while away), and severe (if experience included loss of or damage to property or direct contact with fire e.g., firefighter or } \\
\text { protecting property); 3. Cumulative-the number of ways in which the participant has previously been exposed for fire were added }\end{array}$ \\
\hline Previous fire exposure & $\begin{array}{l}\text { Previous exposure to fire was measured as: 1. Any exposure-yes/no if any previous exposures were indicated; } 2 \text {. Scale-a scale was } \\
\text { created with three levels of exposure-None (not affected, effects were limited to health and/or smoke effects), mild (responses limited to } \\
\text { voluntary evacuation, family or close friend affected, cancellation or alteration of holiday plans/events, business or work affected), and } \\
\text { severe (if experience included forced evacuation, damage to or loss of property, firefighter, first responder, volunteer, protected property, } \\
\text { alert to evacuate, worry about property or risk);Cumulative-The number of ways in which the participant has previously been exposed for } \\
\text { fire were added }\end{array}$ \\
\hline 2003 fires & $\begin{array}{l}\text { For those that indicated previous exposure to fire, no (exposure was a result of another fire event) vs. yes (experience was as a result of } \\
2003 \text { fire in Canberra) }\end{array}$ \\
\hline
\end{tabular}

who reported mild exposure to fire $(2.47 \pm 0.465$ vs. $1.52 \pm$ $0.178 ; p<0.001)$. Previous fire exposure increased the odds of experiencing more physical health symptoms, whether this was defined as any previous exposure $(1.55 \pm 0.182, p<0.001)$, mild or severe exposure $(1.51 \pm 0.181 ; p=0.001,1.82 \pm 0.345 ; p$ $=0.001$, for mild and severe respectively) or as a cumulative measure $(1.40 \pm 0.121 ; p<0.001)$. Having experienced the 2003 Canberra bushfires did not statistically increase the odds of experiencing a greater number of negative physical health symptoms $(1.56 \pm 0.447 ; p=0.124)$. Parental, carer, pregnancy or education status were not associated with an increase in physical health symptoms.

\section{Mental Health}

Over 55\% of responders self-reported symptoms of anxiety (45.3\%) and/or feeling depressed (21.4\%) as a result of the smoke (Table 3). Women were more likely than men to report negative mental health outcomes $(1.99 \pm 0.192, p<0.001)$ which reflected increased symptoms of both anxiety ( $54.5 \mathrm{vs.} 31.8 \%)$ and feelings of depression (25.5 vs. 15.5\%). Poor mental health outcomes were associated with younger age groups (25-54 years groups). Bivariate models (Table 5) identified parents (1.27 $\pm 0.142 ; p=$ $0.029)$, individuals with an existing physical (1.35 $\pm 0.138 ; p=$ $0.004)$ or mental health diagnosis $(1.30 \pm 0.164 ; p=0.038)$, and those who had obtained a higher level of education (high school or lower vs. trade/diploma: $1.46 \pm 0.257, p=0.032$ vs university:
$1.42 \pm 0.208 ; p=0.015)$ had greater odds of experiencing negative mental health outcomes (Table 5). Direct exposure to fire in the current season was associated with increased reported symptoms of anxiety and feeling depressed, according to all measures used ( $\mathrm{p} \leq 0.001$ ). Of note, severe bushfire exposure had a stronger effect on mental health than mild exposure (1.87 \pm 0.344 and $1.46 \pm 0.148$ for severe and mild, respectively). Exposure to fire in a previous season, including during the 2003 Canberra fires, was not associated with mental health outcomes.

\section{Sleep}

Half of survey respondents reported poorer sleep as a result of exposure to smoke (Table 3). This was defined as either disrupted or poor sleep (37.2\%) and/or fatigue or feeling tired (32.5\%). Females were more likely to experience poorer sleep outcomes than men $(1.75 \pm 0.168, p<0.001)$. Odds of poor sleep outcomes were increased in younger age groups. When age and gender were accounted for, those with poorer selfrated health $(2.01 \pm 0.339 ; p<0.001)$, or a previous diagnosis of a physical health condition $(1.34 \pm 0.136 ; p<0.01)$ all had greater odds of experiencing smoke-attributed impairments in sleep (Table 6). Direct exposure to fire in the current fire season increased the odds of poor sleep outcomes, irrespective of the measure used $(p<0.001)$. This effect was more pronounced in those who had experienced more severe exposure $(1.81 \pm 0.326$ vs. $1.34 \pm 0.135$ for mild vs. severe exposure, respectively). The 
TABLE 3 | Proportion of surveyed ACT region residents that experienced health-related symptoms attributed to bushfire smoke during the 2019-20 bushfire season.

\begin{tabular}{|c|c|c|c|}
\hline \multirow{2}{*}{ Symptom } & \multicolumn{3}{|c|}{ Number experiencing the symptom $\mathrm{n}(\%)$} \\
\hline & $n=2,084$ & $n=832$ & $n=1,231$ \\
\hline \multicolumn{4}{|l|}{ Physical symptoms } \\
\hline Eye irritation or watery eyes & $1,525(73.1)$ & $544(65.3)$ & $967(78.6)$ \\
\hline Throat irritation or dry throat & $1,469(70.4)$ & $506(60.8)$ & $950(77.2)$ \\
\hline Headache & $797(38.2)$ & $184(22.1)$ & $607(49.3)$ \\
\hline Breathlessness & $457(21.9)$ & $126(15.0)$ & $326(26.5)$ \\
\hline Sneezing & $437(21.0)$ & $153(18.4)$ & $278(22.6)$ \\
\hline Wheeze or whistling chest & $416(19.9)$ & $103(12.3)$ & 307 (24.9) \\
\hline Chest tightness or pain & $314(15.1)$ & $71(8.5)$ & $242(19.7)$ \\
\hline Diarrhea or gastroenterological symptoms & $51(2.4)$ & $6(0.7)$ & $44(3.6)$ \\
\hline Depression & $447(21.4)$ & $129(15.5)$ & $314(25.5)$ \\
\hline \multicolumn{4}{|l|}{ Sleep-related symptoms } \\
\hline Disrupted or poor sleep & 776 (37.2) & $234(28.1)$ & 535 (43.5) \\
\hline Fatigue or feeling tired & $677(32.5)$ & $187(22.5)$ & $482(39.2)$ \\
\hline
\end{tabular}

Difference between gender $P<0.001$ for all other than sneeze $P=0.022$, and other $P=0.05$.

odds of poor sleep outcomes were increased in the group who had experienced more severe exposures to fire in a previous season $(1.82 \pm 0.312 ; p<0.001)$, and tended to be increased to a lesser extent in the group who had more mild experiences $(1.29 \pm 0.135 ; \mathrm{p}=0.014)$.

\section{Medical Advice}

Approximately $17 \%$ of people reported they sought advice from a health professional or medical facility in relation to their smokeattributed symptoms (Table 7). The most commonly accessed source was a general practitioner (13.2\%), followed by pharmacist (3.6\%) and mental health professional (2\%). Females were more likely to have sought health advice than males (21 vs. $11 \%$, $\mathrm{p}<0.001)$.

\section{DISCUSSION}

The extreme 2019-20 Australian bushfire season increased the burden on the health system (22). The current study indicates substantial self-reported effects of bushfire smoke on the ACT community's physical, mental health and sleep patterns, with almost all respondents reporting at least one negative health effect during this time. The most common symptoms (eye and throat irritation, cough) were consistent with other studies (23) and the known short-term effects of exposure to very high levels of $\mathrm{PM}_{2.5}$. Bushfire smoke-related air pollution reached hazardous levels in the ACT over a longer period and to higher levels than previously reported in other areas of south eastern Australia $(23,24)$. In the current ACT study, $97 \%$ of the sample reported at least one smoke-related health symptom, whereas prevalence of similar health conditions was $65.1 \%$ in the Hunter-New England area $(25,26)$, and $16.1 \%$ in a control population located in Hobart, Tasmania that was not affected by smoke.

The smoke-attributable health burden experienced in the ACT region is higher than other studies of the health effects of smoke (23). Other studies have relied on emergency presentations or hospital records to identify those experiencing negative health outcomes $(8,27-30)$, but the current study drew on self-reported effects from community members, only $\sim 1 \%$ of whom presented at a hospital. Presentation measures only capture medical conditions severe enough for individuals to seek clinical care, therefore underestimating the total health burden. These measures may also miss mental health conditions, for which support may be sought elsewhere. The extent to which this study documents smoke effects is significant and concerning. The prevalence of health conditions for which formal medical advice was not sought highlights the importance of interventions to better prepare people on ways to reduce exposure during periods of hazardous air pollution and when to seek help. Barriers to accessing medical and psychological care were not investigated in this study, but future studies should examine this. Further epidemiological studies that accurately measure individual smoke exposure will be able to better characterize specific health impacts of severe smoke, or thresholds for these, and give more accurate advice about how and when individuals should protect their health.

Smoke exposure is known to exacerbate existing health conditions (14). Our finding that participants with an existing 
TABLE 4 | Ordinal logistic regression examining factors associated with odds of greater number of self-reported physical health symptoms attributed to bushfire smoke exposure.

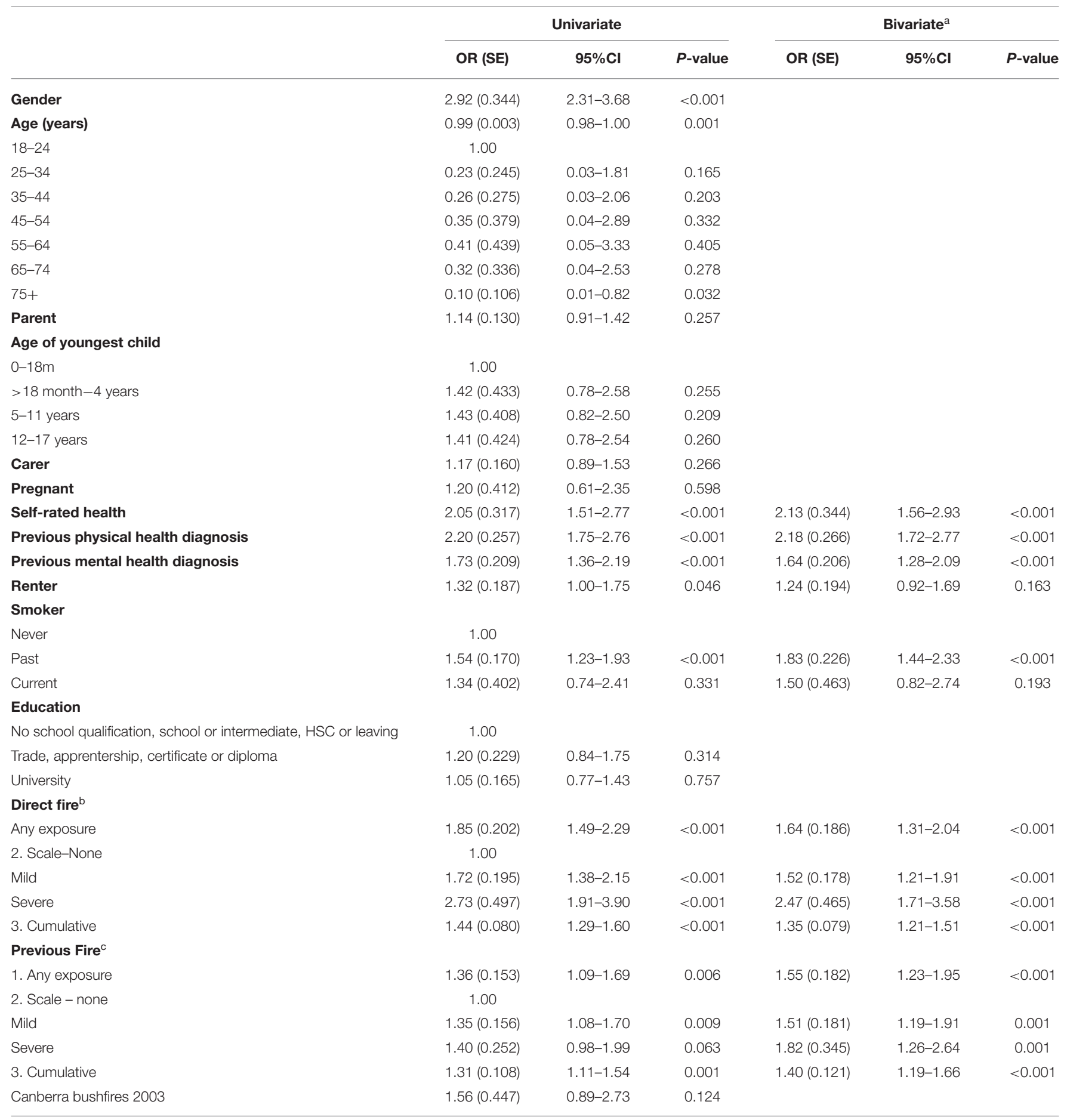

${ }^{a}$ Bivariate models included factors along with gender, age and gender age interaction; ${ }^{b}$ Direct exposure to fire in the current season was measured as: 1 . Any exposure - yes/no if any direct exposures to fire were indicated; 2. Scale-a scale was created consisting of three levels of exposure-none (none or indirect), mild (classified as responses limited to being in an area with fire nearby, evacuation due to bushfire, area of significance lost other than home, family member was affected, home was affected while away), and severe (if experience included loss of or damage to property or direct contact with fire e.g., firefighter or protecting property); 3. Cumulative-the number of ways in which the participant has previously been exposed for fire were added; ${ }^{c}$ Previous exposure to fire was measured as: 1 . Any exposure-yes/no if any previous exposures were indicated; 2 . Scale-a scale was created with three levels of exposure-None (not affected, effects were limited to health and/or smoke effects), mild (responses limited to voluntary evacuation, family or close friend affected, cancellation or alteration of holiday plans/events, business or work affected), and severe (if experience included forced evacuation, damage to or loss of property, firefighter, first responder, volunteer, protected property, alert to evacuate, worry about property or risk); 3. Cumulative-The number of ways in which the participant has previously been exposed for fire were added. 
TABLE 5 | Logistic regression examining factors associated with self-reported negative mental health outcomes attributed to bushfire smoke exposure.

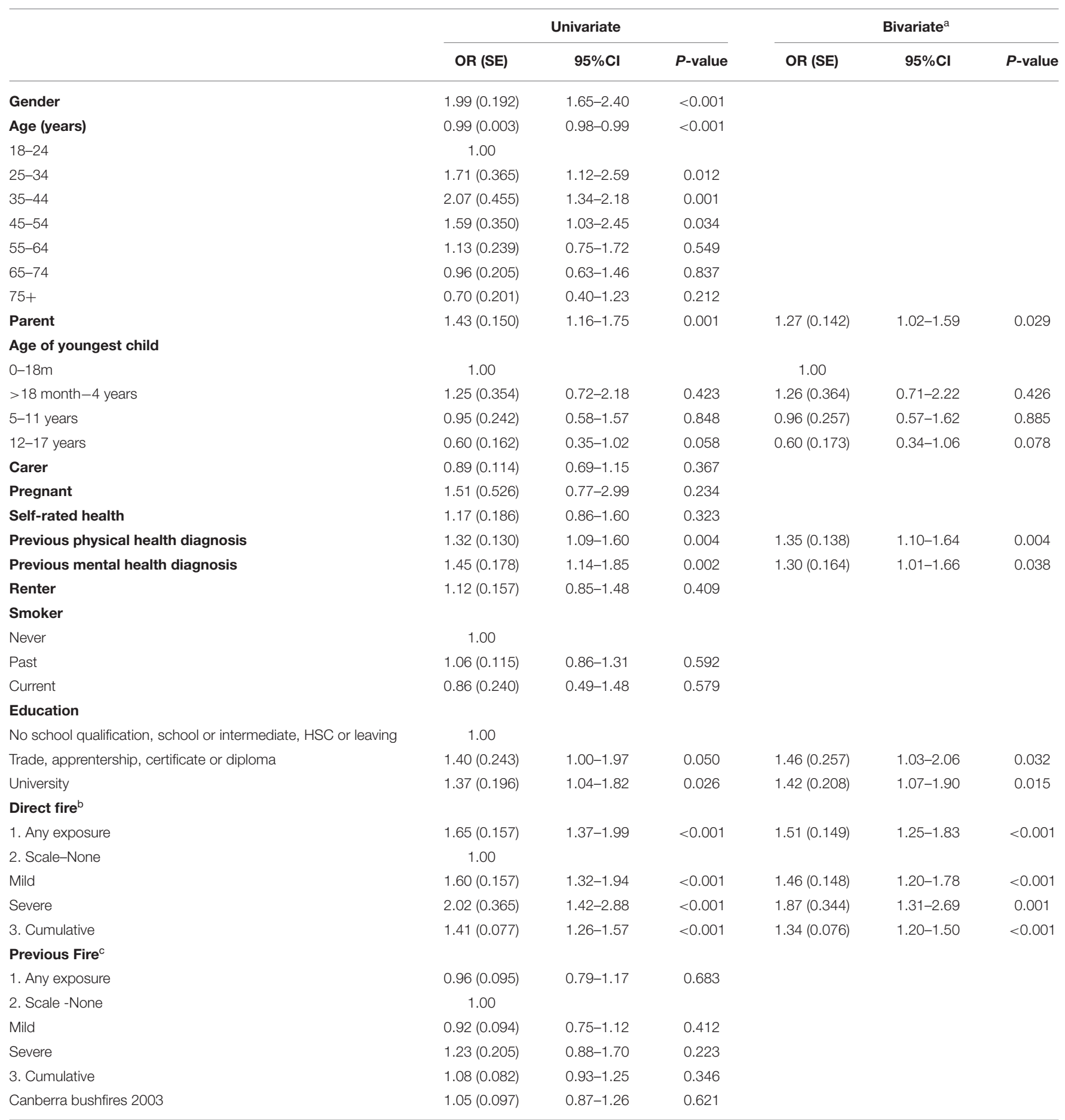

${ }^{a}$ Bivariate models included factors along with gender, age and gender ${ }^{\star}$ age interaction; ${ }^{b}$ Direct exposure to fire in the current season was measured as: 1 . Any exposure-yes/no if any direct exposures to fire were indicated; 2. Scale-a scale was created consisting of three levels of exposure-none (none or indirect), mild (classified as responses limited to being in an area with fire nearby, evacuation due to bushfire, area of significance lost other than home, family member was affected, home was affected while away), and severe (if experience included loss of or damage to property or direct contact with fire e.g., firefighter or protecting property); 3. Cumulative-the number of ways in which the participant has previously been exposed for fire were added; ${ }^{c}$ Previous exposure to fire was measured as: 1 . Any exposure-yes/no if any previous exposures were indicated; 2 . Scale-a scale was created with three levels of exposure-None (not affected, effects were limited to health and/or smoke effects), mild (responses limited to voluntary evacuation, family or close friend affected, cancellation or alteration of holiday plans/events, business or work affected), and severe (if experience included forced evacuation, damage to or loss of property, firefighter, first responder, volunteer, protected property, alert to evacuate, worry about property or risk); Cumulative-The number of ways in which the participant has previously been exposed for fire were added. 
TABLE 6 | Logistic regression examining factors associated with negative self-reported sleep outcomes attributed to bushfire smoke exposure.

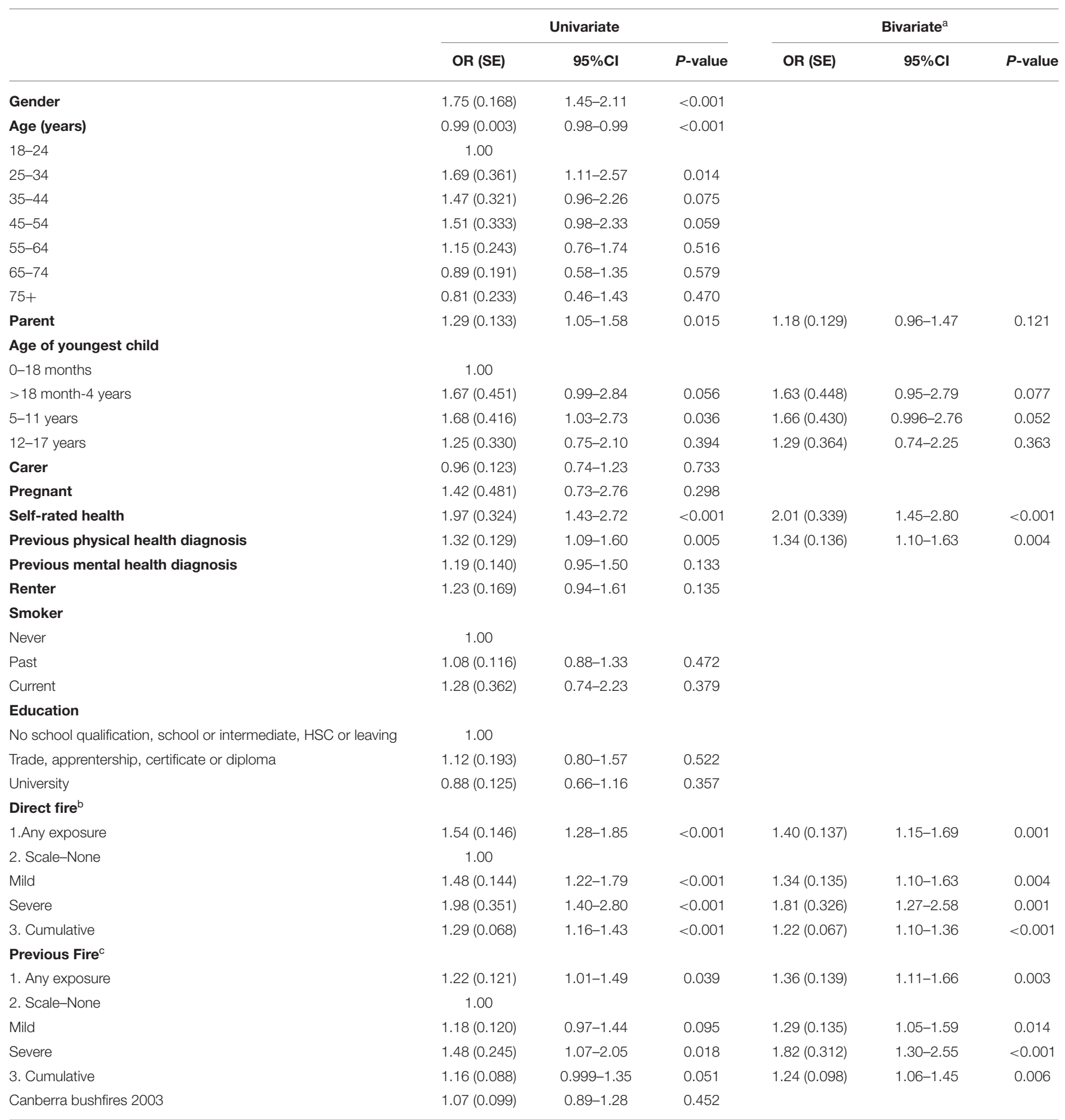

${ }^{a}$ Bivariate models included factors along with gender, age and gender age interaction; ${ }^{b}$ Direct exposure to fire in the current season was measured as: 1 . Any exposure-yes/no if any direct exposures to fire were indicated; 2. Scale-a scale was created consisting of three levels of exposure-none (none or indirect), mild (classified as responses limited to being in an area with fire nearby, evacuation due to bushfire, area of significance lost other than home, family member was affected, home was affected while away), and severe (if experience included loss of or damage to property or direct contact with fire e.g., firefighter or protecting property); 3. Cumulative-the number of ways in which the participant has previously been exposed for fire were added; ; ${ }^{\circ}$ Previous exposure to fire was measured as: 1. Any exposure-yes/no if any previous exposures were indicated; 2. Scale-a scale was created with three levels of exposure-None (not affected, effects were limited to health and/or smoke effects), mild (responses limited to voluntary evacuation, family or close friend affected, cancellation or alteration of holiday plans/events, business or work affected), and severe (if experience included forced evacuation, damage to or loss of property, firefighter, first responder, volunteer, protected property, alert to evacuate, worry about property or risk); 3. Cumulative-The number of ways in which the participant has previously been exposed for fire were added. 
TABLE 7 | Proportion of surveyed ACT region residents that sought medical advice in relation to bushfire smoke attributed health conditions during the 2019-20 bushfire season.

\begin{tabular}{lccc}
\hline & \multicolumn{2}{c}{ Number seeking medical advice $n(\%)$} \\
\cline { 2 - 4 } & Overall & Male & Female \\
\hline $\begin{array}{l}\text { Medical advice from any } \\
\text { source }\end{array}$ & $332(17.1)$ & $80(10.9)$ & $251(21.1)$ \\
General practitioner & $275(13.2)$ & $65(7.8)$ & $209(17.0)$ \\
Pharmacist & $75(3.6)$ & $17(2.1)$ & $58(4.7)$ \\
Mental health professional & $42(2.0)$ & $6(0.7)$ & $36(2.9)$ \\
(e.g., psychologist) & & & $18(1.5)$ \\
Specialist & $22(1.1)$ & $4(0.5)$ & $13(1.1)$ \\
Other health professional & $16(0.8)$ & $3(0.4)$ & $12(1.0)$ \\
Emergency department & $14(0.7)$ & $2(0.2)$ & $5(0.4)$ \\
Hospital inpatient & $8(0.4)$ & $3(0.4)$ & $3(0.2)$ \\
$24 h$ health advice hotline & $6(0.3)$ & $3(0.4)$ &
\end{tabular}

Females were more likely to have sought health advice than males $(p<0.001)$.

health condition had greater odds of experiencing more smokerelated health issues is consistent with this. Similarly, poorer selfrated health was associated with increases in both physical health and sleep-related symptoms. Sleep problems have been associated with both physical and mental health problems $(31,32)$ and physical and mental health are also strongly linked $(33,34)$. Future studies ought to examine the inter-relatedness of these health outcomes (14).

Several studies demonstrate the lasting psychological effects of bushfire exposure, including increased rates of depression, post-traumatic stress disorder (PTSD), and increased drug and alcohol use $(35,36)$. A year after fires in an Australian community, twice as many people (42\%) were classified as "potential psychiatric cases" than in an unexposed comparison population (37). Most people do not develop psychological conditions following a natural disaster (38), but it is important to identify those at risk of doing so and to provide the support they require. Future research should also consider community factors such as community cohesion, competence and support (39) that may influence individual wellbeing, rather than focus solely on individual-level variables.

Women and men may experience, respond to, and recover from bushfires differently $(40,41)$. For example, women are more likely to report higher rates of PTSD $(42,43)$, and men to report an increase in alcohol abuse after experiencing bushfires $(40,44)$. In the current study, women reported higher rates of all physical health symptoms, poorer sleep, and mental health issues. Gender differences have been attributed to biological, social or situational factors $(38,40,45)$.

Longer term mental health outcomes for communities exposed to bushfire are generally good, although a significant minority may experience persistent difficulties and vulnerability may increase with cumulative trauma exposures (44). In our study, previous exposure to fire was associated with greater odds of reporting poorer physical health outcomes and sleep disturbance, but not with mental health outcomes. More disrupted sleep for people who had previously been directly exposed to a bushfire event is possible, as the smoke may have triggered memories of that event. Direct exposure to fire is inherently difficult to understand as exposure severity and personal experience vary among individuals. To investigate this, we explored this measure in several ways-by assessing a binary (yes/no) response, a cumulative measure of the number of effects identified, or a ranking measure, in which some experiences were weighted more strongly than others. Unsurprisingly, people who were directly affected by fire had increased odds of physical, sleep, and negative mental health outcomes. For all of these outcomes, the pattern of relationship was similar, with higher odds ratios in the group ranked severe, compared to the mild group. The different ways of measuring exposure were all statistically significant, suggesting the link between direct experience of bushfire with adverse health outcomes is robust. In contrast, the cumulative measure showed consistently weaker odds ratios compared to other measures. This poses questions about the level of detail needed in measuring people's objective and subjective experience with bushfire, whether there are severity of impact thresholds for concern, and how a single measure might account for different experiences of a similar event (for example voluntary vs. forced evacuation). The complexity of this issue warrants more detailed study.

Although participants in this study were asked to focus on the effects of smoke (and not fire) specifically, it is likely some people were unable to separate the effects of smoke from other factors, such as heat stress or the direct effects of fire. Also, this study coincided with the early stages of the COVID-19 pandemic in Australia, and participants may have been unable to disentangle their feelings of distress and anxiety about the bushfires from the uncertainty of the developing pandemic.

During the 2019-20 bushfire season, there was community concern about whether smoke exposure would have long-term effects on health (46). This continues to be an area that is not well understood as only limited studies have explored long-lasting or delayed effects of smoke on health. Some have identified increased incidence of influenza (47) and impaired lung function (48) for months to years after a fire event. Canberra had experienced a severe bushfire in January 2003 and a survey 3 years after this disaster found that for over half the survey respondents $(56.4 \%, \mathrm{n}=272)$ the bushfire did not have a lasting effect on their overall health and $2.5 \%(n=12)$ reported that their overall health was better than before (18). However, $40.9 \%$ $(n=197)$ reported a lasting negative effect of the bushfire on their overall health. As such, we hypothesized that community members who had been exposed to the 2003 bushfires in Canberra may have been at greater risk of negative health effects during the 2019-20 fire season, particularly regarding negative mental health outcomes. However, this was not evident from our results, perhaps indicating that people were resilient and had had sufficient time to resolve any adverse reactions to the 2003 fires. Further longitudinal research is needed to understand the long-lasting, as well as the acute, health effects of bushfire and smoke exposure.

Rapid research during or immediately following natural disasters is challenging $(49,50)$. Here, a survey was designed to 
be deployed quickly to capture a broad snapshot of a population's health in response to a bushfire smoke event. Online data collection was suitable for a wide range of the population, but not when such as electricity or internet services are interrupted. The use of multiple sampling approaches captured experiences from a broad cross-section of the population, though the sample is not representative of the whole population as some groups such as the elderly, those with no fixed address, or those for whom English is not their primary language, may have been missed or underrepresented. Further, the focus here was on rapid and easy to measure self-report items with good face validity, rather than on more sophisticated measures of key constructs such as mental health. Despite these limitations, important trends concerning health and lifestyle burdens were identified, presenting an effective way to screen for specific areas or groups requiring more detailed examination. This method should, though, be refined to focus on the most pertinent and useful information to ensure ease of completion and associated rapid delivery of appropriate support and services to communities.

\section{CONCLUSIONS}

Bushfire smoke can have considerable and underestimated effects on physical and mental health, beyond those associated with direct contact with fire and the acute effects of smoke inhalation. Greater understanding of mental health and long-term health effects is needed, particularly for at-risk groups, including parents, those with existing health conditions, or those who had previous exposure to fire and smoke. Improved public health communication is needed to strengthen individuals' ability to prevent harm and protect the health of themselves and their families for future events.

\section{REFERENCES}

1. Particulate matter data from ACT air quality monitoring stations [Internet]. (2020) Available online at: https://www.data.act.gov.au/Environment/ Particulate-Matter-data-from-ACT-Air-Quality-Monit/ufvu-jybu.

2. NSW Department of Planning IaE. About the air quality categories 2020 . (2020) Available online at: https://www.environment.nsw.gov.au/topics/air/ understanding-air-quality-data/air-quality-categories.

3. Di Virgilio G, Evans JP, Blake SA, Armstrong M, Dowdy AJ, Sharples J, et al. Climate change increases the potential for extreme wildfires. Geophys Res Lett. (2019) 46:8517-26. doi: 10.1029/2019GL083699

4. van Oldenborgh GJ, Krikken F, Lewis S, Leach NJ, Lehner F, Saunders KR, et al. Attribution of the Australian bushfire risk to anthropogenic climate change. Natural Hazards and Earth System Sciences Discussions. (2020) 1-46. doi: 10.5194/nhess-21-941-2021

5. Liu JC, Pereira G, Uhl SA, Bravo MA, Bell ML, A. systematic review of the physical health impacts from non-occupational exposure to wildfire smoke. Environ Res. (2015) 136:120-32. doi: 10.1016/j.envres.2014.10.015

6. Duc HN, Chang LT-C, Azzi M, Jiang N. Smoke aerosols dispersion and transport from the $2013 \mathrm{New}$ South Wales (Australia) bushfires. Environ Monit Assess. (2018) 190:1-22. doi: 10.1007/s10661-018-6810-4

7. Johnston FH, Henderson SB, Chen Y, Randerson JT, Marlier M, DeFries RS, et al. Estimated global mortality attributable to smoke from landscape fires. Environ Health Perspect. (2012) 120:695-701. doi: 10.1289/ehp.1104422

\section{DATA AVAILABILITY STATEMENT}

The raw data supporting the conclusions of this article will be made available by the authors, without undue reservation.

\section{ETHICS STATEMENT}

The studies involving human participants were reviewed and approved by Human Research Ethics Committee of the Australian National University (protocol number: 2020/029). The patients/participants provided their written informed consent to participate in this study.

\section{AUTHOR CONTRIBUTIONS}

RR, AS, AC, BC, AL, JL, JR, ST, SV, and IW contributed to the conception and design of the study. ST and RR obtained ethics approval, conducted data collection, and database management. $\mathrm{RR}$ was responsible for data analysis and drafting of manuscript. All authors contributed to manuscript revision, read, and approved the submitted version.

\section{FUNDING}

This research was funded by the Australian National University College of Health and Medicine. AC is supported by a National Health and Medical Research Council (NHMRC) Fellowship 1173146.

\section{ACKNOWLEDGMENTS}

The authors would like to thank the community members who participated in this study.

8. Dennekamp M, Abramson MJ. The effects of bushfire smoke on respiratory health. Respirology. (2011) 16:198-209. doi: 10.1111/j.1440-1843.2010.01868.x

9. Hamon R, Tran HB, Roscioli E, Ween M, Jersmann H, Hodge S. Bushfire smoke is pro-inflammatory and suppresses macrophage phagocytic function. Sci Rep. (2018) 8:1-11. doi: 10.1038/s41598-018-31459-6

10. Shaposhnikov D, Revich B, Bellander T, Bedada GB, Bottai M, Kharkova $\mathrm{T}$, et al. Mortality related to air pollution with the Moscow heat wave and wildfire of 2010. Epidemiology. (2014) 25:359. doi: 10.1097/EDE.00000000000 00090

11. Johnston F, Hanigan I, Henderson S, Morgan G, Bowman D. Extreme air pollution events from bushfires and dust storms and their association with mortality in Sydney, Australia 1994-2007. Environ Res. (2011) 111:8116. doi: 10.1016/j.envres.2011.05.007

12. Faustini A, Alessandrini ER, Pey J, Perez N, Samoli E, Querol X, et al. Shortterm effects of particulate matter on mortality during forest fires in Southern Europe: results of the MED-PARTICLES Project. Occup Environ Med. (2015) 72:323-9. doi: 10.1136/oemed-2014-102459

13. Reid CE, Brauer M, Johnston FH, Jerrett M, Balmes JR, Elliott CT. Critical review of health impacts of wildfire smoke exposure. Environ Health Perspect. (2016) 124:1334-43. doi: 10.1289/ehp.1409277

14. Rappold AG, Reyes J, Pouliot G, Cascio WE, Diaz-Sanchez D. Community vulnerability to health impacts of wildland fire smoke exposure. Environ Sci Technol. (2017) 51:6674-82. doi: 10.1021/acs.est.6b 06200 
15. Vardoulakis S, Jalaludin BB, Morgan GG, Hanigan IC, Johnston FH. Bushfire smoke: urgent need for a national health protection strategy. Med J Aust. (2020) 212:349. doi: 10.5694/mja2. 50511

16. Borchers Arriagada N, Palmer AJ, Bowman D, Morgan GG, Jalaludin BB, Johnston FH. Unprecedented smoke-related health burden associated with the 2019-20 bushfires in eastern Australia. Med J Aust. (2020). doi: 10.5694/mja2.50545

17. Johnston FH, Borchers-Arriagada N, Morgan GG, Jalaludin B, Palmer AJ, Williamson GJ, et al. Unprecedented health costs of smoke-related $\mathrm{PM}_{2.5}$ from the 2019-20 Australian megafires. Nature Sustainability. (2021) 4:427. doi: 10.1038/s41893-020-00610-5

18. Camilleri P, Healy C, Macdonald EM, Nicholls S, Sykes J, Winkworth G, et al. Recovery from bushfires: The experience of the 2003 Canberra bushfires three years after. JEmergency Primary Health Care. (2010) 8:9903831. doi: 10.33151/ajp.8.1.112

19. Harris PA, Taylor R, Thielke R, Payne J, Gonzalez N, Conde JG. Research electronic data capture (REDCap) — a metadata-driven methodology and workflow process for providing translational research informatics support. J Biomed Inform. (2009) 42:377-81. doi: 10.1016/j.jbi.2008. 08.010

20. Batterham PJ, Sunderland M, Carragher N, Calear AL, Mackinnon AJ, Slade T. The Distress Questionnaire-5: Population screener for psychological distress was more accurate than the K6/K10. J Clinical Epidemiol. (2016) 71:35-42. doi: 10.1016/j.jclinepi.2015. 10.005

21. Australian Bureau of Statistics. 2016 Census QuickStats-Australian Capital Territory Australian Bureau of Statistics. (2016). Available online at: https:// quickstats.censusdata.abs.gov.au/census_services/getproduct/census/2016/ quickstat/8ACTE

22. Lal A, Patel M, Hunter A, Phillips C. Towards resilient health systems for increasing climate extremes: insights from the 2019-20 Australian bushfire season. Int $J$ Wildland Fire. (2021) 30:1-5. doi: 10.1071/WF 20083

23. Kolbe A, Gilchrist KL. An extreme bushfire smoke pollution event: health impacts and public health challenges. N S W Public Health Bull. (2009) 20:19-23. doi: 10.1071/NB08061

24. Horsley JA, Broome RA, Johnston FH, Cope M, Morgan GG. Health burden associated with fire smoke in Sydney, 2001-2013. Med J Aust. (2018) 208:30910. doi: $10.5694 / \mathrm{mja} 18.00032$

25. Moberley S, Carlson S, Durrheim D, Dalton C. Flutracking: Weekly online community-based surveillance of influenzalike illness in Australia, 2017 Annual Report. Communicable Diseases Intelligence. (2019) 43. doi: 10.33321/cdi.2019. 43.31

26. Howard Z, Carlson S, Baldwin Z, Johnston F, Durrheim D, Dalton C. High community burden of smoke-related symptoms in the Hunter and New England regions during the 2019-2020 Australian bushfires. Public Health Res Practice. (2020). doi: 10.17061/phrp301 22007

27. Martin KL, Hanigan IC, Morgan GG, Henderson SB, Johnston FH. Air pollution from bushfires and their association with hospital admissions in Sydney, Newcastle and Wollongong, Australia 1994-2007. Aust N Z J Public Health. (2013) 37:238-43. doi: 10.1111/1753-6405. 12065

28. Johnston FH, Kavanagh AM, Bowman DM, Scott RK. Exposure to bushfire smoke and asthma: an ecological study. Med J Aust. (2002) 176:5358. doi: 10.5694/j.1326-5377.2002.tb04551.x

29. Walter CM, Schneider-Futschik EK, Knibbs LD, Irving LB. Health impacts of bushfire smoke exposure in Australia. Respirology. (2020) 25:495501. doi: 10.1111/resp. 13798

30. Tham R, Erbas B, Akram M, Dennekamp M, Abramson MJ. The impact of smoke on respiratory hospital outcomes during the 2002-2003 bushfire season, Victoria, Australia. Respirology. (2009) 14:69-75. doi: 10.1111/j.1440-1843.2008. 01416.x
31. Stein MB, Belik S-L, Jacobi F, Sareen J. Impairment associated with sleep problems in the community: relationship to physical and mental health comorbidity. Psychosom Med. (2008) 70:9139. doi: 10.1097/PSY.0b013e3181871405

32. Reid KJ, Martinovich Z, Finkel S, Statsinger J, Golden R, Harter K, et al. Sleep: a marker of physical and mental health in the elderly. Am J Geriatric Psychiat. (2006) 14:860-6. doi: 10.1097/01.JGP.0000206164.56 404.ba

33. Ohrnberger J, Fichera E, Sutton M. The relationship between physical and mental health: A mediation analysis. Soc Sci Med. (2017) 195:429. doi: 10.1016/j.socscimed.2017.11.008

34. Surtees P, Wainwright N, Luben R, Wareham N, Bingham S, Khaw K-T. Psychological distress, major depressive disorder, and risk of stroke. Neurology. (2008) 70:788-94. doi: 10.1212/01.wnl.0000304109.18 563.81

35. Parslow RA, Jorm AF. Tobacco use after experiencing a major natural disaster: analysis of a longitudinal study of 2063 young adults. Addiction. (2006) 101:1044-50. doi: 10.1111/j.1360-0443.2006.0 1481.x

36. Finlay SE, Moffat A, Gazzard R, Baker D, Murray V. Health impacts of wildfires. PLoS Currents. (2012) 4:e4f959951cce959952c. doi: 10.1371/4f95995 $1 \mathrm{cce} 2 \mathrm{c}$

37. McFarlane AC, Clayer J, Bookless C. Psychiatric morbidity following a natural disaster: an Australian bushfire. Soc Psychiatry Psychiatr Epidemiol. (1997) 32:261-8. doi: 10.1007/BF00789038

38. Bonanno GA, Brewin CR, Kaniasty K, Greca AML. Weighing the costs of disaster: Consequences, risks, and resilience in individuals, families, and communities. Psychological Science in the Public Interest. (2010) 11:1-49. doi: 10.1177/15291006103 87086

39. Pooley JA, Cohen L, O’Connor M. Bushfire communities and resilience: What can they tell us? Aust J Emerg Managem. (2010) 25:33-8. Available online at: https://knowledge.aidr.org.au/resources/ajem-apr-2010-bushfirecommunities-and-resilience-what-can-they-tell-us/

40. Cavanagh A, Wilson CJ, Kavanagh DJ, Caputi P. Men and women's psychological outcomes in communities affected by bushfires. Aust Community Psycholog. (2018) 29:91. Available online at: https://psychology. org.au/getmedia/3559ba7a-be82-40be-8069-fea4822e77be/cavanagh-et-alacp-vol-29-2-2018.pdf

41. Eriksen C, Gill N, Head L. The gendered dimensions of bushfire in changing rural landscapes in Australia. J Rural Stud. (2010) 26:33242. doi: 10.1016/j.jrurstud.2010.06.001

42. Olff M, Langeland W, Draijer N, Gersons BP. Gender differences in posttraumatic stress disorder. Psychol Bull. (2007) 133:183. doi: 10.1037/0033-2909.133.2.183

43. Steinglass P, Gerrity E. Natural disasters and post-traumatic stress disorder short-term versus long-term recovery in two disaster-affected communities. J Appl Soc Psychol. (1990) 20:1746-65. doi: 10.1111/j.1559-1816.1990.tb0 1509.x

44. Bryant RA, Waters E, Gibbs L, Gallagher HC, Pattison P, Lusher D, et al. Psychological outcomes following the Victorian Black Saturday bushfires. Aust N Zealand J Psychiat. (2014) 48:634-43. doi: 10.1177/00048674145 34476

45. Moreno-Walton L, Koenig K. Disaster resilience: Addressing gender disparities. World Med Health Policy. (2016) 8:46-57. doi: 10.1002/wm h3.179

46. Jalaludin B, Johnston F, Vardoulakis S, Morgan G. Reflections on the catastrophic 2019-2020 Australian bushfires. The Innovation. (2020) 1. doi: 10.1016/j.xinn.2020. 04.010

47. Landguth EL, Holden ZA, Graham J, Stark B, Mokhtari EB, Kaleczyc E, et al. The delayed effect of wildfire season particulate matter on subsequent influenza season in a mountain west region of the USA. Environ Int. (2020) 139:105668. doi: 10.1016/j.envint.2020.105668

48. Orr A, AL Migliaccio C, Buford M, Ballou S, Migliaccio CT. Sustained effects on lung function in community members following exposure to hazardous 
$\mathrm{PM}_{2.5}$ levels from wildfire smoke. Toxics. (2020) 8:53. doi: 10.3390/toxics80 30053

49. Galea S, Maxwell AR, Norris F. Sampling and design challenges in studying the mental health consequences of disasters. Int J Methods Psychiatr Res. (2008) 17:S21-S8. doi: 10.1002/ mpr.267

50. Kessler RC, Keane TM, Mokdad A, Ursano RJ, Zaslavsky AM. Feature Paper: Methodological issues in post-disaster mental health needs assessment research. Peachtree City, Georgia: Conference on Health Survey Research Methods. (2007). p. 33.

Conflict of Interest: The authors declare that the research was conducted in the absence of any commercial or financial relationships that could be construed as a potential conflict of interest.
Publisher's Note: All claims expressed in this article are solely those of the authors and do not necessarily represent those of their affiliated organizations, or those of the publisher, the editors and the reviewers. Any product that may be evaluated in this article, or claim that may be made by its manufacturer, is not guaranteed or endorsed by the publisher.

Copyright (๑) 2021 Rodney, Swaminathan, Calear, Christensen, Lal, Lane, Leviston, Reynolds, Trevenar, Vardoulakis and Walker. This is an open-access article distributed under the terms of the Creative Commons Attribution License (CC BY). The use, distribution or reproduction in other forums is permitted, provided the original author(s) and the copyright owner(s) are credited and that the original publication in this journal is cited, in accordance with accepted academic practice. No use, distribution or reproduction is permitted which does not comply with these terms. 